\title{
Finite element analysis of concrete-encased steel composite columns with off-center steel section
}

\author{
B.L. Lai ${ }^{\mathrm{a}}$, J. Y. Richard Liew ${ }^{\mathrm{a}, \mathrm{b} *}, \mathrm{~S} . \mathrm{Li}^{\mathrm{a}}$ \\ ${ }^{a}$ Department of Civil and Environmental Engineering, National University of Singapore, Singapore \\ ${ }^{\mathrm{b}}$ College of Civil Engineering, Nanjing Tech University, China \\ *Corresponding author, e-mail address: ceeljy@nus.edu.sg
}

\begin{abstract}
Concrete encased steel composite columns have been widely used in high-rise buildings and top-down constructions owning to excellent load-carrying capacity and fire resistance. However, double symmetric composite section is rarely achieved due to the off-center eccentricity of steel kingpost, which is a common problem in top-down constructions. EN1994-1-1 (EC4) simplified method does not provide any explicit provisions for this kind of irregular composite columns, and many designers address this issue by reducing it into a symmetrical cross-section for ease of simple calculation. This paper presents a general method based on nonlinear finite element modelling software ABAQUS to analyze the ultimate strength behavior of concrete-encased composite columns with asymmetrically placed steel section. The accuracy of the FE model is verified against existing test results. Parametric study is performed to further investigate the influence of steel section eccentricity on ultimate strength of stub columns under different loading conditions. A simplified method based on modification of EC4 design approach is developed to construct the moment-axial force interaction diagram. Accuracy of the proposed method is assessed by comparing the analytically predicted results with the numerical results. It is found that the proposed method can be adopted as a useful tool to predict the cross-section resistance of non-symmetrical concrete-encased steel composite columns.
\end{abstract}

Keywords: Encased composite columns; off-centered section; top-down construction; finite element analysis; EC4 simplified method.

\section{Introduction}

Concrete-encased steel composite columns gains increasingly popularity in top-down construction owing to its excellent load-carrying capacity. A considerable volume of research has been carried out to study the structural behavior of encased composite columns by Zhu et al. [1], Kim et al. [2] and Dundar et al. [3]. Following the stipulation specified in various design codes, including Eurocode 4 [4] and American code AISC 360-10 [5], the majority of experimental study focused on columns with steel section positioned exactly at the geometrical centroid of the overall cross-section. However, for basement construction, non-symmetrical cross-sections were always generated since the steel kingposts may be constructed with non-negligible offcenter eccentricity. Off-centered placement of steel profile was mostly caused by construction error but also can be done on purpose due to architectural requirement as pointed out by Roik et al. [6]. Based on the provisions stated in current design code, these irregular crosssections cannot be properly handled without suitable numerical assistance. Chiorean [7] proposed an incremental-iterative procedure to predict interaction diagram and moment capacity contours for arbitrarily-shaped composite crosssections. Chan et al. [8] developed a graphically interactive computer program capable of performing cross-section analysis and secondorder analysis using PEP element.

This paper present nonlinear Finite Element Analysis (FEA) on normal strength concreteencased steel composite columns with off-center steel section, of which the load-carrying capacity is comprehensively analyzed by varying the load eccentricity and the encased steel section 
eccentricity. A simplified design method is proposed to predict cross-sectional strength based on modification of EC4 plastic design approach, and verification of the proposed method is conducted by comparing with FEA result and numerical procedure developed by Chan et al. [8].

\section{Calibration of FEA}

Only a handful of experimental study on nonsymmetric composite columns with I-shaped steel section are reported in literature. Numerical simulation is performed based on the specimen details reported in [9].

\subsection{Review of experimental work}

The cross section dimensions of specimens tested by Roik [9] are shown in Fig. 1. All steel columns are partially encased and one side of steel flange is exposed without any concrete cover, generating an eccentricity of steel profile along direction paralleled to web with magnitude of $40 \mathrm{~mm}$ for specimen SRC11-13 and $50 \mathrm{~mm}$ for specimen SRC21-23, respectively. Other specimen details are tabulated in Table 1, indicating the effective length, load eccentricity, concrete compressive strength, steel yield strength, as well as yield strength of longitudinal reinforcement. It should be noted that the positive sign of "e" denotes that axial force is applied in the reverse direction of off-centered steel section, while negative sign means axial force is applied with the same eccentric direction as embedded steel. The yield strength of both flange and web are listed. As can be identified from the strength given in parentheses, steel web yields at larger strength than flange due to the thinner plate thickness. All specimens are reinforced with stirrups spaced at $170 \mathrm{~mm}$ interval in the middle segment and $80 \mathrm{~mm}$ at the end region. Stirrups are not enclosed due to the eccentric placement of steel, hence they are welded to the web as described in [9].

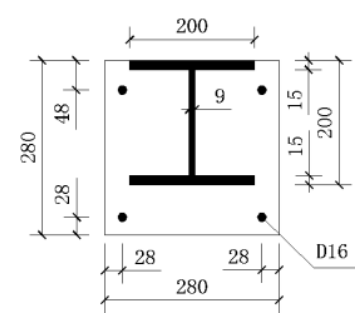

SRC11-13

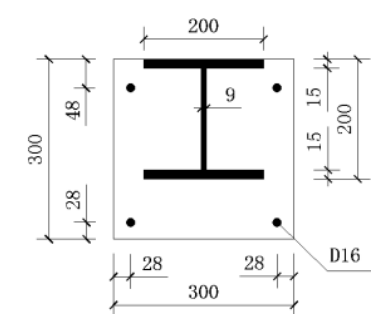

SRC21-23
Fig. 1. Cross-section dimension of specimens in [9].
Table 1. Details of specimens in [9].

\begin{tabular}{cc}
\hline Specimen & Specimen details \\
\hline SRC11 & L3460+e0+C37.4+S206(220)+R420 \\
SRC12 & L3460+e40+C37.4+S206(220)+R420 \\
SRC13 & L3460+e-100+C37.4+S206(220)+R420 \\
SRC21 & L5460+e-10+C31.6+S285(305)+R420 \\
SRC22 & L5460+e30+C31.6+S285(305)+R420 \\
SRC23 & L5460+e-110+C31.6+S285(305)+R420 \\
\hline
\end{tabular}

\subsection{Numerical model}

Nonlinear Finite Element Analysis (FEA) is conducted employing ABAQUS software package, and the numerical result is compared with test result for calibration purpose. Given the fact that stress-strain law of respective materials were not reported in original literature [9], all material properties input in FE model follow the specification in Eurocode 2 [10] for concrete and Eurocode 3 [11] for steel.

As depicted in Fig. 2, C3D8R element is selected for meshing steel and concrete component while the reinforcement cage is meshed using T3D2 element. The interfacial bond behavior between encased steel section and concrete is simulated by defining a surface-tosurface contact algorithm with the surrounding concrete functioning as master surface while the encased steel working as slave surface, and the tangential behavior is modelled using penalty formulation with friction coefficient valued 0.25 as adopted by Ellobody et al. [12]. Both top and bottom of column are tied to an endplate, which guarantees the uniform force transfer to the entire cross-section. Reference point is coupled to the endplate for the ease of load application. Longitudinal and transverse reinforcement are merged into a whole part and embedded in concrete. Mesh-sensitivity study was conducted to find the optimal mesh size catering for both accuracy and computational effort.

Pin-pin connection is achieved by releasing the freedom of rotation about $\mathrm{Y}-\mathrm{Y}$ direction for both top and bottom reference points as illustrated in Fig. 2. Axial translation is also set free at the top, permitting the displacement control as utilized in the experimental program [9]. 


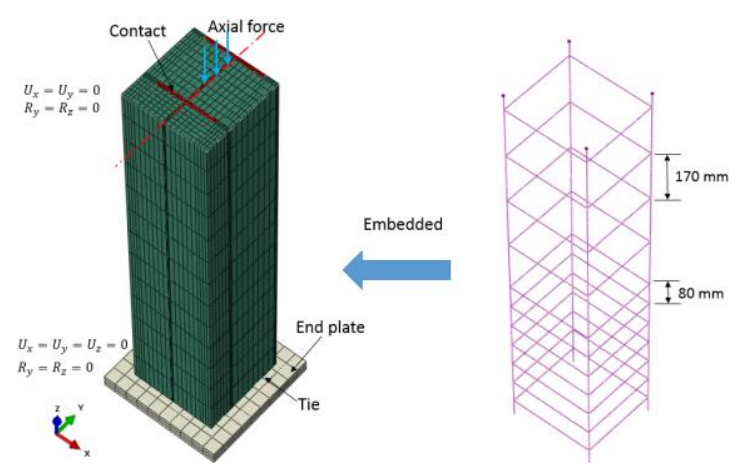

Fig. 2. Typical finite element model of column specimen (half model).

\subsection{Verification of FE model}

The numerically obtained ultimate capacity is taken as the peak load of load-axial shortening response. Since only the maximum axial load was reported in literature [9] while bending moment was not available, the calibration of established FE model is completely based on the comparison of axial force.

As compared in Table 2, FEA result is quite close to test result with the ratio fluctuating in a narrow range from 0.914 to 1.027 , and the average ratio is 0.977 , revealing high level of accuracy.

Table 2. Comparison of ultimate resistance between test result and numerical result.

\begin{tabular}{cccc}
\hline Specimen & $\begin{array}{c}\text { Test result } \\
\boldsymbol{N}_{\boldsymbol{t}}(\mathbf{k N})\end{array}$ & $\begin{array}{c}\text { FEA result } \\
\boldsymbol{N}_{\boldsymbol{a}}(\mathbf{k N})\end{array}$ & $\boldsymbol{N}_{\boldsymbol{a}} \boldsymbol{N} \boldsymbol{N}_{\boldsymbol{t}}$ \\
\hline SRC11 & 3617 & 3713 & 1.027 \\
SRC12 & 2825 & 2581 & 0.914 \\
SRC13 & 1800 & 1690 & 0.939 \\
SRC21 & 3938 & 3991 & 1.013 \\
SRC22 & 2640 & 2607 & 0.988 \\
SRC23 & 1608 & 1576 & 0.980 \\
Mean & & & 0.977 \\
\hline
\end{tabular}

\section{Parametric study}

Using the calibrated numerical model, more comprehensive analysis is carried out by undertaking parametric study. Since the main focus of this paper is to predict the cross-section resistance of off-centered concrete-encased steel composite columns, and to generate the relation between load-carrying capacity and steel section eccentricity, all the proposed specimens in parametric study are designed as $600 \mathrm{~mm}$-long stub columns with cross-section dimension of 300x300 and steel section eccentrically placed $25 \mathrm{~mm}$ and $50 \mathrm{~mm}$ apart from geometric centroid along minor axis. For comparative purpose, specimen with steel section positioned exactly at center is also studied as a control group. Axial compression force is applied with eccentricity varying from $0 \mathrm{~mm}$ to $600 \mathrm{~mm}$. Normal strength concrete C50 and normal strength steel S355 is investigated, and the reinforcement cage is designed with yield strength of $500 \mathrm{MPa}$.

As shown in Fig. 3, the proposed specimens are categorized into three groups according the magnitude of steel section eccentricity. Longitudinal and transverse reinforcement bar are $12 \mathrm{~mm}$ and $8 \mathrm{~mm}$ in diameter, and link spacing is designed as $100 \mathrm{~mm}$. Concrete covering thickness defined as the distance between steel section surface and adjacent concrete surface satisfied EC4 provision. In the direction of steel eccentricity, the summation of cover thickness on both sides is considered and compared twice of the limit value stipulated in EC4 [4]:

$c_{z, b}+c_{z, t} \leq 0.6 h_{z}$

Where $c_{z, b}$ and $c_{z, t}$ refer to the bottom and top cover of the steel profile and $h_{z}$ is the height of steel section.
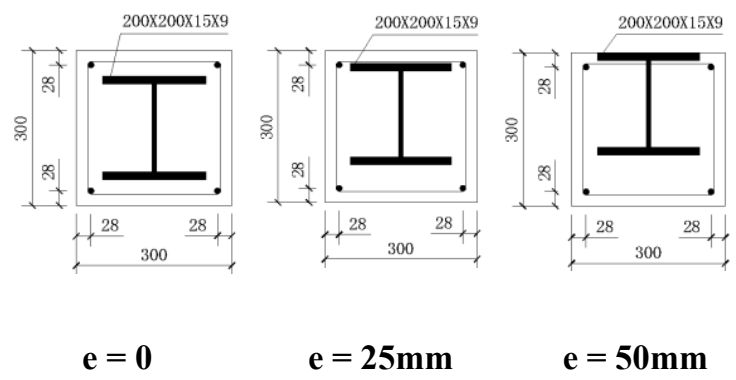

Fig. 3. Cross-section dimension of proposed specimens.

Fig. 4 plots the ultimate strength degradation curve with the increase of load eccentricity for both regular encased columns and off-centered encased columns. It should be noted that when load eccentricity exceeds $200 \mathrm{~mm}$, all curves almost coincide with each other and hard to be distinguished. For illustration purpose, only the ultimate strength generated under compression force with eccentricity less than $200 \mathrm{~mm}$ is presented in Fig. 4. 


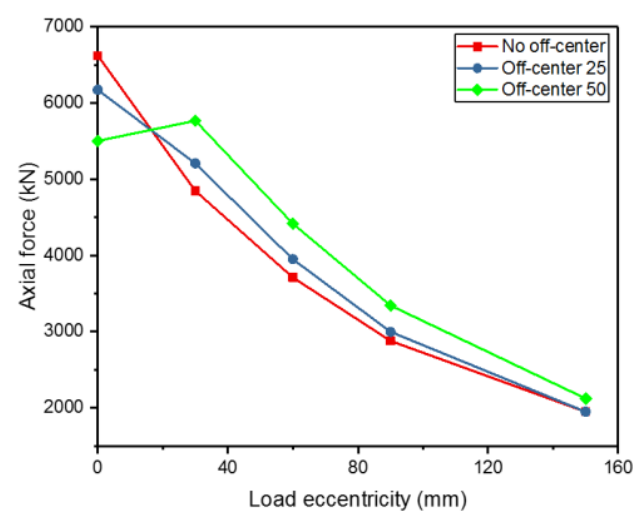

(a)

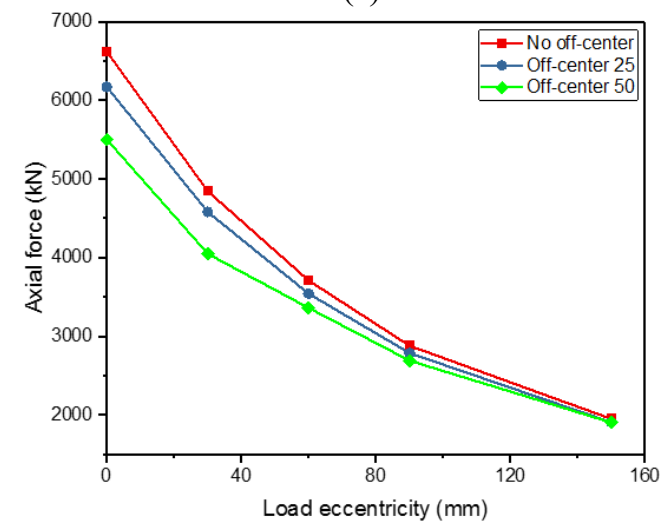

(b)

Fig. 4. FEA result of ultimate strength: (a) Load eccentricity in same direction of steel section eccentricity; (b) Load eccentricity in opposite direction of steel section eccentricity.

As can be seen from Fig. 4(a), in the case that axial load is applied in the same eccentric direction of steel section, encased stub columns with off-centered steel section exhibit higher load-carrying capacity compared with the standard non-off-centered composite columns, and the further the steel section eccentrically placed, the more significant the strength enhancement is. On the other hand, when axial force is applied in the reverse direction, ultimate strength decrease with the increase of steel section eccentricity as indicated in Fig. 4(b). It should be noted when axial compression is concentrically applied, the regular stub column can sustain highest load since no additional moment will be generated, and the strength discrepancy among the three groups becomes less significant as the load eccentricity increase. For explanation purpose, "Plastic centroid" is incorporated as demonstrated in Fig. 5, of which the coordinate can be calculated from Eq. (2-3)

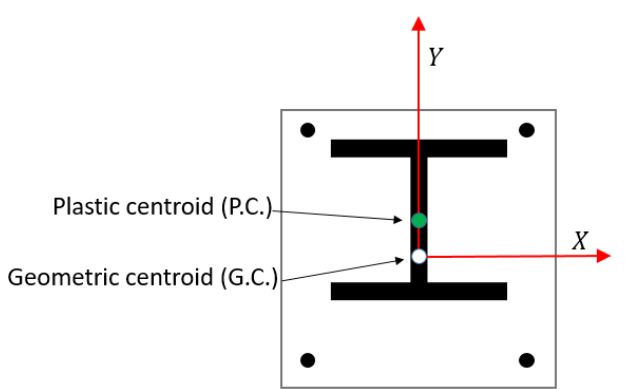

Fig. 5. Comparison between "Geometric centroid" and "Plastic centroid".

$$
\begin{aligned}
& X_{p c}=\frac{A_{c} X_{c} f_{c}+A_{r} X_{r} f_{r}+A_{s} X_{s} f_{s}}{A_{c} f_{c}+A_{r} f_{r}+A_{s} f_{s}} \\
& Y_{p c}=\frac{A_{c} Y_{c} f_{c}+A_{r} Y_{r} f_{r}+A_{s} Y_{s} f_{s}}{A_{c} f_{c}+A_{r} f_{r}+A_{s} f_{s}}
\end{aligned}
$$

In the general case of composite columns with unsymmetrically reinforced cross-section, concentric load is said to be located at the "Plastic centroid" [13]. Nevertheless, concentric load is still defined to be passing through "Geometric centroid" in this paper for ease of illustration. Therefore, when axial force is applied in the same direction of steel section eccentricity, load eccentricity corresponding to the origin of "Plastic centroid" will be less than the regular cross-section, and it is also possible that eccentric compression may lead to higher resistance than concentric compression, which has been confirmed as demonstrated in Fig. 4(a). Similarly, the strength degradation trend shown in Fig. 4(b) can be explained using the same principle.

It should be further noted that the pure bending test is not modelled in this paper since no experimental proof can be found for calibration. Instead, influence of steel placement eccentricity on the flexural capacity will be analytically studied in the following proposed procedure.

\section{Proposed design method}

Current EC4 simplified method does not provide any explicit provision for the design of unsymmetrical composite cross-sections, and the general method requires the assistance of numerical technique. A simplified procedure based on modification of EC4 method is proposed for predicting the cross-sectional 
capacity of encased composite columns with offcentered steel section. Full range of axial forcebending moment interaction diagram can be constructed by addressing both cases that outer flange under compression and inner flange under compression. For simplicity, outer flange is defined as the one near concrete surface, while inner flange refers to the one away from concrete surface.

In the case of outer flange under compression, the entire composite section can be subdivided into a reduced symmetrical crosssection and pure concrete portion as illustrated in Fig. 6. For ease of calculation, longitudinal bars also move into the reduced section hence producing unified covering thickness. Pure compression point can be obtained as follow:

$$
\begin{aligned}
& N=N_{t}+N_{b} \\
& M=N_{t} \times e-N_{b} \times e_{0}
\end{aligned}
$$

For pure bending scenario, the flexural resistance of the composite cross-section can be treated as equal to the reduced symmetrical cross-section, since the remaining concrete part will not contribute to flexural capacity, the determination of plastic neutral axis and plastic moment follows the same procedure in EC4 [4].

For another two points locating between pure compression and pure bending point on the N-M curve, EC4 simplified is also applicable to determine axial resistance and corresponding bending moment. The concrete component sketched using dash line falls into the tension part, hence it can be neglected in the computation of intermediate point 1 and point 2 . However, EC4-based bending moment should be transferred to be with respect to the centerline of entire cross-section as formulated as Eq. (6).

$$
M=M^{\prime}+N \times e
$$

In another case with outer flange under tension, the pure compression point is the same as discussed above. For the determination of other three points, composite cross-section are extended to generated symmetric one by adding the fictitious portion enclosed by dash line as illustrated in Fig. 7. Bending moment computed based on EC4 shall also be transformed using Eq. (6) to be with respect to centerline of the original cross-section.

It should be noted that EC4 adopts reduction factor $\alpha_{M}$ to reflect the difference between plastic stress distribution and real stress distribution for uniaxial bending. For S355, 0.9 is selected for strength reduction. In the proposed method, $\alpha_{M}=0.9$ is also adopted for consistency.
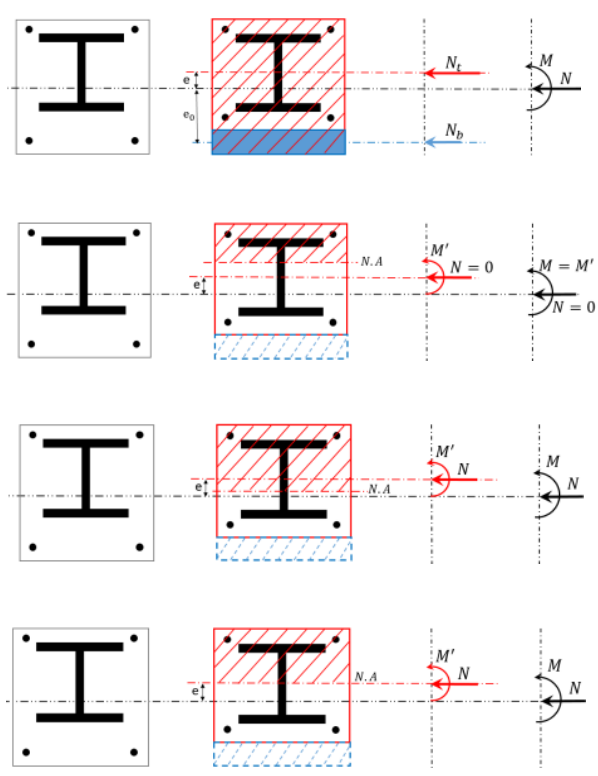

Fig. 6. Proposed procedure for N-M curve construction: Outer flange under compression. (a) Pure compression point; (b) Pure bending point; (c) Intermediate point 1; (d) Intermediate point 2.
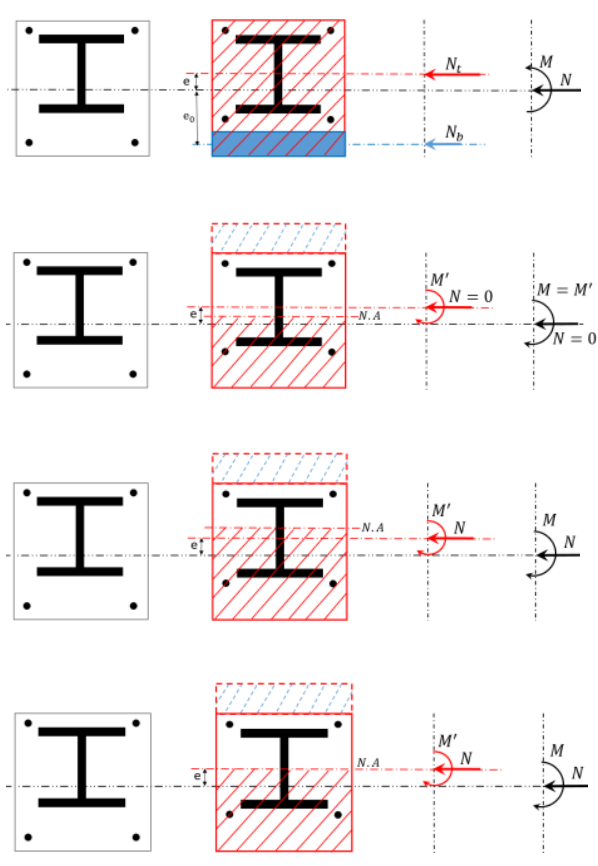

Fig. 7. Proposed procedure for N-M curve construction: Inner flange under compression. (a) Pure compression point; (b) Pure bending point; (c) Intermediate point 1; (d) Intermediate point 2.

For comparison, the computer program developed by Chan is also used to generate cross-sectional interaction diagram as plotted in 
Fig. 8, and the portion with negative axial force is removed since it is rarely considered in design.

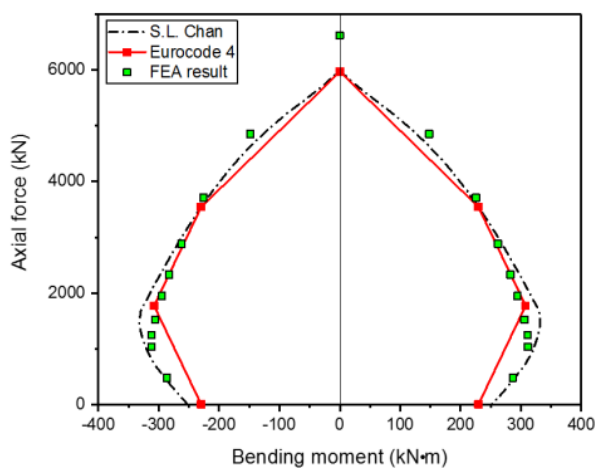

(a) $\mathrm{e}=0 \mathrm{~mm}$

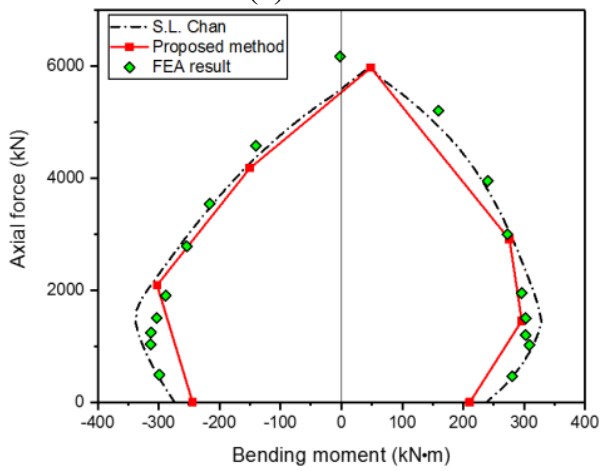

(b) $\mathrm{e}=25 \mathrm{~mm}$

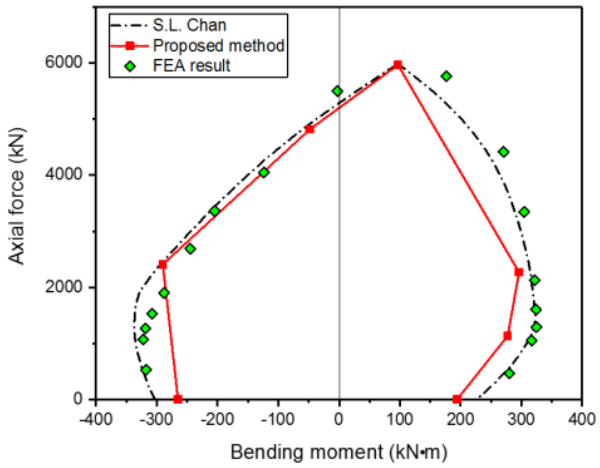

(c) $\mathrm{e}=50 \mathrm{~mm}$

Fig. 8. Comparison of cross-section N-M curves between proposed method and numerical result.

Following the recommendations proposed EC4 [4], the maximum concrete compressive stress input in the Chan's model is set as $0.85 f_{c}$. As indicated from Fig. 8, the proposed N-M curve agrees well with FEA result regardless of the bending direction. In addition, the proposed method also gives close prediction to Chan's model despite the slight errors existed between the polygonal curve constructed by straight lines connecting several feature points and the accurate diagram produced using numerical technique. Therefore, the newly developed method can be adopted as a useful design tool to approximate the cross-section resistance of unsymmetrical encased columns with normal strength materials.

The effect of steel section eccentricity on cross-section resistance is also comparatively interpreted in Fig. 9 and it can be clearly identified that the interaction curve below and above balanced point present different variation trend.

As demonstrated in the left portion of Fig. 9 (a) and (b), if load eccentricity is opposite to steel eccentric position, the ultimate resistance decrease with the increase of steel section eccentricity in the case of high axial compression. However, when bending moment dominate the design, the cross-section with the furthest off-centered steel possess the highest resistance, especially for pure bending scenario, which is fairly reasonable since most of concrete is subjected to compression while the steel section falls into the tension zone. For the right side potion of Fig. 9, the axial and flexural capacity variation exhibit the opposite tendency.

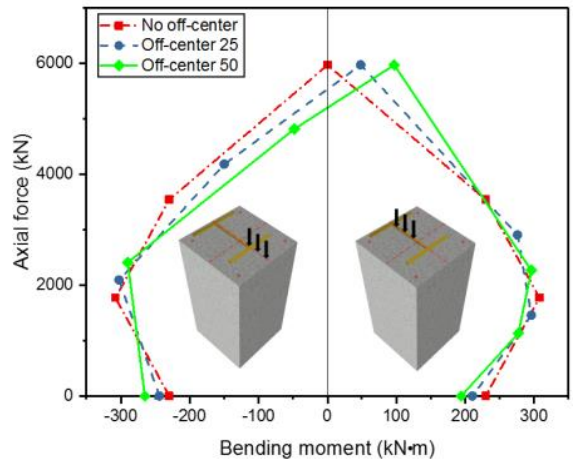

(a)

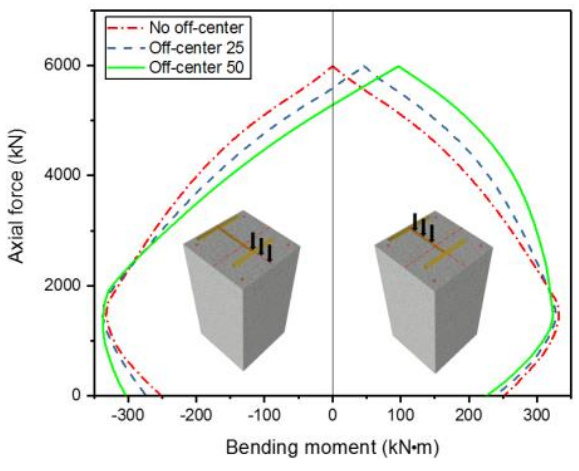

(b)

Fig. 9. Comparison of cross-section N-M curves between symmetrical cross-sections and nonsymmetrical cross-sections: (a) Proposed model; (b) Chan's model. 


\section{Conclusions}

Numerical and analytical studies are conduced to investigate the load-carrying capacity of concrete encased steel stub columns with non-symmetrical cross-sections. A new method based on modification of EC4 approach is proposed for predicting the cross-section resistance. The following conclusions are derived based on the study reported:

1) The off-centered distance of the steel section affected the ultimate resistance of concrete encased steel stub column, including its compression and flexural resistance.

2) In the case of uniaxial bending with outer flange under compression, the eccentricity of steel section leads to higher resistance in the N-M curve above the balanced point. Whereas for the N-M curve below the balance point, the eccentricity leads to lower resistance. In the case of uniaxial bending with inner flange under compression, the steel section eccentricity exerts a reverse effect.

3) For composite flexural members, the non-symmetrical cross-section with outer flange under compression leads to lower flexural capacity while the cross-section with inner flange under compression exhibits higher flexural resistance as compared with regular double symmetrical cross-sections.

4) The proposed method can be adopted as a tool for predicting the cross-sectional resistance of non-symmetrical concreteencased steel composite columns with normal strength materials.

\section{Acknowledgement}

The research is funded by the Building \& Construction Authority of Singapore under project grant R-302-000-168-409.

\section{References}

[1] Zhu WQ, Meng G, Jia JQ. Experimental studies on axial load performance of high-strength concrete short columns. Proceedings of the Institution of Civil Engineers-Structures and Buildings 2014; 167(9): 509-19.

[2] Kim CS, Park HG, Chung KS, Choi IR. Eccentric axial load testing for concrete-encased steel columns using $800 \mathrm{MPa}$ steel and $100 \mathrm{MPa}$ concrete. Journal of Structural Engineering 2011; 138(8): 1019-31.

[3] Dundar C, Tokgoz S, Tanrikulu AK, Baran T. Behaviour of reinforced and concrete-encased composite columns subjected to biaxial bending and axial load. Building and environment 2008; 43(6): 1109-20.

[4] EN 1994-1-1. Eurocode 4: Design of Composite Steel and Concrete Sructures-Part 1-1. General Rules and Rules for Buildings; 2004.

[5] AISC 360-10. Specification for structural steel buildings. Chicago, USA: American Institute of Steel Construction (AISC); 2010.

[6] Roik K, Bergmann R. Design method for composite columns with unsymmetrical crosssections. Journal of Constructional Steel Research 1990; 15(1-2): 153-68.

[7] Chiorean CG. Computerised interaction diagrams and moment capacity contours for composite steel-concrete cross-sections. Engineering Structures 2010; 32(11): 3734-57.

[8] Liu SW, Liu YP, Chan SL. Advanced analysis of hybrid steel and concrete frames: part 1: crosssection analysis technique and second-order analysis. Journal of Constructional Steel Research 2012; 70: 326-36.

[9] Roik K, Bergmann R. Composite columnsdesign and examples for construction. In Composite and mixed construction; 267-278. ASCE; 1985.

[10]EN 1992-1-1, Eurocode 2: Design of Concrete Structures-Part 1-1: General Rules and Rules for Buildings; 2004.

[11]EN 1993-1-1, Eurocode 3: Design of Steel Structures-Part 1-1: General Rules and Rules for Buildings; 2005.

[12] Ellobody E, Young B. Numerical simulation of concrete encased steel composite columns. Journal of Constructional Steel Research 2011; 67(2): 211-22.

[13]Hsu TT, Mo YL. Unified theory of concrete structures. John Wiley \& Sons; 2010. 